\title{
Perceived work-related psychosocial stress and musculoskeletal disorders complaints among call centre workers in India-a cross sectional study
}

\begin{abstract}
Context: The study was conducted in Chennai, India in response to increase in number of health complaints among call centre workers in an organization.

Aim: To assess the relationship between work-related musculoskeletal disorders and workplace psychological stress.

Settings and designs: Cross-sectional study design.

Methods and materials: After obtaining informed consent, data was collected using selfreported questionnaire distributed to 155 call centre workers in the organization.

Statistical analysis used: Chi-square test, t-test \& general logistic regression.

Results: From the worker's perception, it was found that $65.8 \%$ of the participants have average level of mental stress at work. Among the various work-related psychological stressors, things happening outside of control at work had the highest impact on most of the subjects $(84.5 \%)$. The most frequent physical pain/discomfort experienced by the study participants in the previous 12 -month period concerned the neck region (53.5\%). Statistical analysis showed significant association between the prevalence of MSD and occupational mental stress.

Conclusion: Occupational/workplace mental stress has a significant positive association with prevalence of MSD among call centre workers. A systematic approach to risk reduction addressing the organizational, psychosocial and physical work factors is required. More research is required to know about the interaction between psychological stress and MSD.
\end{abstract}

Keywords: MSD, call centre workers, occupational mental stress
Volume 5 Issue 2 - 2018

\author{
Nafeesa MAC,' 'Vidhya Venugopal,' Anbu \\ Vijayalakshmi P, ${ }^{2}$ Rajkumar $\mathrm{P}^{\mathrm{I}}$ \\ 'Department of environmental Health Engineering, Sri \\ Ramachandra University, India \\ ${ }^{2}$ College of Allied Health Sciences, Sri Ramachandra University, \\ India
}

Correspondence: Vidhya Venugopal, Professor, Department of environmental Health Engineering, Sri Ramachandra University, Porur, Chennai-I I6, India, Tel +91-9710830010, Email vvidhya@ehe.org.in

Received: August 30, 2017 | Published: March 12, 2018
Abbreviations: MSD, musculoskeletal disorders; BPOs, business process outsourcing, BOSS, burnout stress syndrome

\section{Introduction}

BPOs (Business Process Outsourcing) are typically categorized into back office outsourcing or non-voice sector and front office outsourcing or voice based sector. While the non-voice process includes data encoding, database development, market research, handling of credit billing problems, loan processing, account management etc, the voice sector is often interchangeably referred to as the 'Call Centre industry' because the service entails interactive communication with the client or customers over the telephone. ${ }^{1}$ The call centre industry has emerged as one of the largest private sector employers in India, providing direct/indirect employment to more than 4.5 million people, with about $50 \%$ of employees around 25 years of age. The industry has grown by about $17 \%$ during the recent years providing more job opportunities. ${ }^{1}$ The nature of job in call centres leads to 'Burnout Stress Syndrome' (BOSS) characterized by chronic fatigue, insomnia and alteration of the 24-hour biological rhythm, which affects not only sleep but also proper functioning of the other body functions. Apart from the sedentary and unhealthy lifestyle which can lead to physical health problems, work pressure may also affect one's mental, physical and psychosocial health.
Studies with telecommunication employees using questionnaire have shown impacts on musculoskeletal issues and mental stress associated with seven psychosocial variables. ${ }^{2}$ Evidence from a study with female computer

users demonstrated that the interaction of physical and psychosocial factors in the work place has a stronger association with neck pain and disability than the presence of either factor alone. ${ }^{3}$ Professional workers are often encouraged to perform long hours of computers work with high mental demands to meet deadlines at a hectic workplace resulting in heightened muscle tension and forces along with inadequate work breaks ${ }^{4}$ that can lead to burn outs in the employees. Most frequent MSD complaints with call handlers is usually concerned with the cervical region, visual fatigue, vocal disturbance and psychological disturbances and the MSD disorders are significantly greater in workers with psychological distress. ${ }^{5}$ Data processors who report chronic pain, especially with high prevalence rate in the neck area, are more likely to be dissatisfied with the jobs, to report a lack of choice in deciding what they did at work or to receive help from others whetting was limited. ${ }^{6}$

A study in Korea also reported overall prevalence of musculoskeletal symptoms and depressive symptoms were $53.7 \%$ and $20.6 \%$ respectively in call centre workers. The study also reported that the relationship between high risk occupational stress group of the total 
scores, physical environment, job demand and interpersonal conflict to the reported musculoskeletal symptoms was significant. ${ }^{7}$ Call centre workers who perceived higher job stress also had significantly increased risk of several health complaints, including musculoskeletal disorders. ${ }^{89}$ Comfort of the work environment showed the strongest association with symptoms in the neck/ shoulder or arm/ hand in the either type of complaints were: low complexity of work, long total time of customer call person day continuous computer work without a break, high psychological demands, low decision authority, lack of support from colleagues and superiors. ${ }^{10} \mathrm{~A}$ Brazil at a telemarketing operations showed that the physical arrangement of the workstation, duration in the job and the low level of satisfaction study emerged as the factors most related to neck- shoulder and hand- wrist MSD induced time away from work. ${ }^{11}$

A cross sectional study conducted by Angelo D' Errico et al., ${ }^{12}$ with a sample size of 775 workers in Turin, Northern Italy showed that the risk of neck- shoulder symptoms was also significantly associated with poor supervisor support or recognition, insufficient duration of breaks, years of exposure in the Call Centre sector, low job control, job insecurity, high demand and high job strain part from physical conditions such as workstation, workplace environmental conditions such as elevated noise, poor lighting, insufficient workspace and lack of ventilation. ${ }^{12}$

Though several studies have been done outside of India, considering the large workforce employed in BPOs in India, there is severe lack of studies, except a handful few ${ }^{13-16}$ to assess the workrelated occupational health risks faced by the call centres workers. In such context, it becomes important that studies addressing the issue in question are conducted in India to bring in the research understanding, knowledge and evidence to help build upon existing occupational health policies that can be implemented as effective prevention policies to help avert current and future health risks for millions of workers in the BPOS. One of the studies that studied the influence of psychosocial workplace factors on occurrence of musculoskeletal discomfort in computer operators which highlights the need for such studies to be done in workers engaged with computer work stations. ${ }^{16}$ The lack of studies conducted in India to understand the relationship between workplace psychological stress and musculoskeletal disorders, inspired the initiation of the study as the investigators thought it was imperative to address the issue. The study was aimed at determining and documenting association, if any, between perceived workplace psychological stress and musculoskeletal disorders complaints among call centre workers.

\section{Materials and methods}

A cross-sectional study was performed on a sample of 155 call centre workers employed in a call centre in Chennai. The study was conducted over a period of about 5 months from January 2016 to May 2016. The call centre had about 657 employees in total working on the phones. People who had been working at a call centre in an 8-hour shift for at least 1 year were included. People who are working less than one year and with pre-existing musculoskeletal disorders symptoms of other disease origin were excluded from the study. $14 \%$ of the 657 employees were excluded due to the exclusion criteria. Though the Nordic questionnaire was given to about $40 \%$ of the employees in the firm with the management's approval, $9 \%$ percent of the employees did not return the filled-in Nordic questionnaire and hence could not participate in the psychosocial stress study and $4 \%$ of the employees could not participate in the interviews for various reasons, including loss of interest. About $27 \%$ of the qualified employees agreed to participate in the study and were interviewed and included in the study. The study was approved by the Institutional Ethics Committee of Sri Ramachandra University. A permission letter to conduct the study was obtained from the Senior Management of the call centre.

Two types of questionnaire were used to collect the required data. The Cohen PSS questionnaire was administered via a face to face interview. The informed consent had a confidentiality statement that agreed to keep the employee ID to be kept anonymous by a coding system. The names of the participants were not collected and the individual questionnaire results were not shared with the management which was agreed upon before the initiation of the study.

A. The Nordic Musculoskeletal Questionnaire was used to determine the presence of musculoskeletal symptoms in any specified body region, their impact and any remedial measure taken during the previous 12 months.

B. The Cohen perceived stress scale (PSS) was used to assess the mental stress of the participants. Perceived Stress Scale (PSS) is a self-report measure of stress. PSS is the most widely used psychosocial instrument to measure the perception of stress. It is a measure of the degree to which situations in one's life are appraised as stressful. The 10 Items in this questionnaire were designed to tap the perceptions of workers on how unpredictable, uncomfortable and overloaded respondents find their lives at their workplace. The total score is calculated by finding the sum of the 10 items and reverse coding for certain questions $(4,5,7, \& 8)$. The PSS has a range of scores between 0 and 40 and a higher score indicates more stress. ${ }^{17}$

A list of about 20 stressors was formulated based on previous similar studies and circulated through the company employees and were to requested rank the stressors in an ascending order. The most picked and highly ranked stressors were selected for the questionnaire in the cross-sectional study. The questions asked about the travel time, mode of transportation, excess workload and any reason for the employee wanting to quit the job due to stress factors were to elicit the perceived stress factors due to these factors. The responses from these questions are expected to give the stress factors that influence their job stress and consequently their musculoskeletal complaints, if any association exists.

\section{Statistical analysis}

$\mathrm{R}$ software was used for the statistical analysis. Association between the occupational mental stress and musculoskeletal disorders were assessed by chi-square $\left(\mathrm{X}^{2}\right)$ test, and odds ratios were performed setting the significance threshold at 0.05 . Linear logistic regression was performed to adjust for known confounders such as age, gender and MSD injuries due activities such gym.

\section{Results and discussion \\ Demographic characteristics}

The study population consisted mainly of males $(67.7 \%)$ with a mean age of 27.5 years followed by the females $(32.3 \%)$. The proportion of employees, who qualified after the meeting the inclusion criteria, who participated in the study was about $27 \%$. Most of the working class people were predominantly in the age group of 24-30yrs $(50.96 \%)$, who had few years of experience in the field and fresher (12-24months) were in the age group of 20-23yrs (34.2\%). A small 
percent of the study participants $(\sim 3 \%)$ of the employees frequented the gym or engaged themselves in sports activities. Among the study participants, many workers $(36.7 \%)$ travelled a distance of more than $10 \mathrm{~km}$ every day to reach their workplace for various reasons, which is not surprising as the study was conducted in a metro city. The main mode of transportation used by the most of the study participants was public transport (54.19\%). The average travel time for $36.7 \%$ of the study participants to reach the workplace was within 30 minutes. The questionnaire also elicited information that $61.9 \%$ of the participants do overtime in a week as shown in Table 1.

Table I Socio-demographic characteristics of the study participants

\begin{tabular}{|c|c|c|c|}
\hline \multirow{2}{*}{$\begin{array}{l}\text { SI. } \\
\text { no }\end{array}$} & \multicolumn{2}{|c|}{ Socio-demographic characteristics } & \multirow{2}{*}{$\begin{array}{l}\text { Frequency } \\
(\mathbf{N}),(\%) \\
105(67.7)\end{array}$} \\
\hline & Gender & Males & \\
\hline \multirow{3}{*}{2.} & & Females & $50(32.2)$ \\
\hline & Age category & $20-30 y r$ & $132(85.1)$ \\
\hline & & $31-40 y r$ & $23(14.8)$ \\
\hline \multirow{3}{*}{3.} & & $0-3 \mathrm{~km}$ & $38(24.5 I)$ \\
\hline & $\begin{array}{l}\text { Travelling distance to } \\
\text { work }\end{array}$ & $3-6 \mathrm{~km}$ & $30(19.35)$ \\
\hline & & $7-10 \mathrm{~km}$ & $30(19.3)$ \\
\hline \multirow{5}{*}{4.} & & $>10 \mathrm{~km}$ & $57(36.7)$ \\
\hline & & $\begin{array}{l}\text { Company } \\
\text { transport }\end{array}$ & $3(1.9)$ \\
\hline & transportation & Private transport & $39(25.1)$ \\
\hline & & Public transport & $84(54.1)$ \\
\hline & & Others & $29(18.7)$ \\
\hline \multirow{3}{*}{5.} & & $<30$ mins & $57(36.7)$ \\
\hline & Travel time to work & $31-60$ mins & $53(34.1)$ \\
\hline & & $61-90$ mins & $27(17.4)$ \\
\hline \multirow{3}{*}{6.} & & $>90$ mins & $18(\mid 1.6)$ \\
\hline & $\begin{array}{l}\text { Overtime in a week } \\
\text { (approx.) }\end{array}$ & Yes & $96(61.9)$ \\
\hline & & No & $59(38.0)$ \\
\hline \multirow[b]{2}{*}{7.} & & 12 to 20 & $117(75.4)$ \\
\hline & Tenure (months) & 21 to 30 & $28(\mid 8.0)$ \\
\hline \multirow{6}{*}{8.} & & 31 to 40 & $10(6.4)$ \\
\hline & & $\begin{array}{l}\text { Long working } \\
\text { hours }\end{array}$ & $\mathrm{II}(7.0)$ \\
\hline & $\begin{array}{l}\text { Reasons to want to } \\
\text { quit the job in future }\end{array}$ & Job insecurity & $2(1.2)$ \\
\hline & & Personal problems & $30(19.3)$ \\
\hline & & Distance to office & $15(9.6)$ \\
\hline & & Other reasons & $97(62.5)$ \\
\hline
\end{tabular}

\section{Perceived causes for stress}

Out of the 155 participants, based on their responses to the Cohen PSS, $27.7 \%$ were found to have high level of job stress, $65.8 \%$ have reported average levels of job stress, whereas only a small percentage of respondents $(6.4 \%)$ had perceived mild level of stress at work (Figure 1).

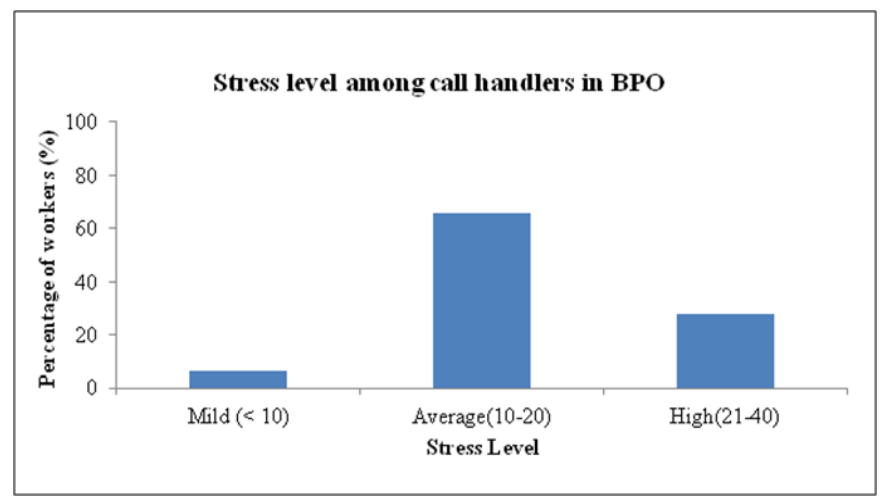

Figure I Distribution of Occupational stress levels among the Call Centre employees in a BPO in Chennai.

Based on a preliminary survey conducted with the employees in the call centre before the actual study started as to what was perceived as stressors by the employees, the work-related stressors was divided into 5 categories, viz.

a. Work pressure.

b. Things happening out of control at work.

c. Not able to cope up with work and its demands.

d. Work-related dissatisfaction (lack of decision making opportunities) and

e. Job insecurity (Figure 2).

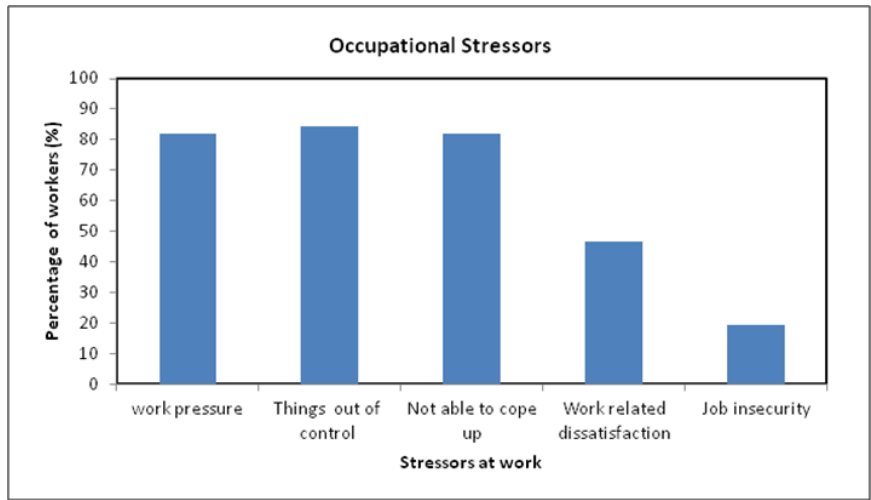

Figure 2 Occupational stressors.

Among the various stressors, 'things happening outside of control' at work had the highest impact on most of the subjects $(84.5 \%)$, followed by work pressure $(81.9 \%)$ and not being able to cope with work pressures \& demands $(81.9 \%)$. Work related dissatisfaction such as work allocation/dissatisfaction with promotion or rewards and interpersonal issues with peers or managers related to work had moderate impact on the participants (46.5\%) and job insecurity was found to have had the least impact among all the stress factors $(19.5 \%)$. 


\section{Musculoskeletal disorders}

MSDs assessed for the participants was based on the participants' recall of their MSDs issues in the previous 12-month period using the Nordic questionnaire and the results are as shown in Table 2.

Table 2 Distribution of Musculoskeletal complaints among the study participants

\begin{tabular}{|c|c|c|c|c|}
\hline \multirow[t]{2}{*}{ SI. no } & \multirow{2}{*}{$\begin{array}{l}\text { Musculoskeletal Issues in } \\
\text { various body parts }\end{array}$} & \multicolumn{3}{|c|}{ Number of participants - n (Frequency -\%) } \\
\hline & & $\begin{array}{l}\text { With MSD } \\
\text { complaints }\end{array}$ & $\begin{array}{l}\text { MSD preventing them from } \\
\text { carrying Normal activities }\end{array}$ & $\begin{array}{l}\text { Consulted a physician } \\
\text { regarding MSD }\end{array}$ \\
\hline I. & Neck & $83(53.5)$ & $37(23.8)$ & $19(12.3)$ \\
\hline 2. & Shoulders & $57(36.7)$ & $25(16.2)$ & $16(10.3)$ \\
\hline 3. & Upper back & $52(33.5)$ & $20(12.9)$ & $14(9.0)$ \\
\hline 4. & Elbows & $25(16.1)$ & $\mathrm{II}(7.0)$ & $6(3.9)$ \\
\hline 5. & Wrists/Hands & $57(36.7)$ & $30(19.3)$ & $15(9.7)$ \\
\hline 6. & Lower back & $32(20.6)$ & $23(14.8)$ & $10(7.7)$ \\
\hline 7. & Hips/Thighs & $35(22.5)$ & $20(12.9)$ & $12(4.5)$ \\
\hline 8. & Knees & $33(21.2)$ & $22(14.1)$ & $7(7.7)$ \\
\hline 9. & Ankles/Feet & $33(2 \mid .2)$ & $15(9.6)$ & $12(6.5)$ \\
\hline
\end{tabular}

The most frequent MSD complaints as perceived by the employees over the previous 12-month period concerned the neck region $(53.5 \%)$, followed by the shoulder and wrist region $(36.8 \%)$. Onethird of the respondents reported upper back trouble (33.5\%) while complaints in the elbows were found to be lesser than complaints in other regions $(16.1 \%)$. Overall, only $25.2 \%$ of the respondents with MSD complaints had consulted a physician for treatment their condition (Figure 3).

The results of occurrence of MSDs as perceived by the participants under the influence of stress showed that stress due to 'things happening out of control' at work that was related to job was reported by maximum number of participants, whereas 'job insecurity' was the least impact stressor (Table 3). Statistical analysis of the results showed significant positive association was found between occupational stress and perceived MSD complaints by the participants (X-squared $=30.8858, \mathrm{df}=1$, p-value $=2.737 \mathrm{e}-08$ ).

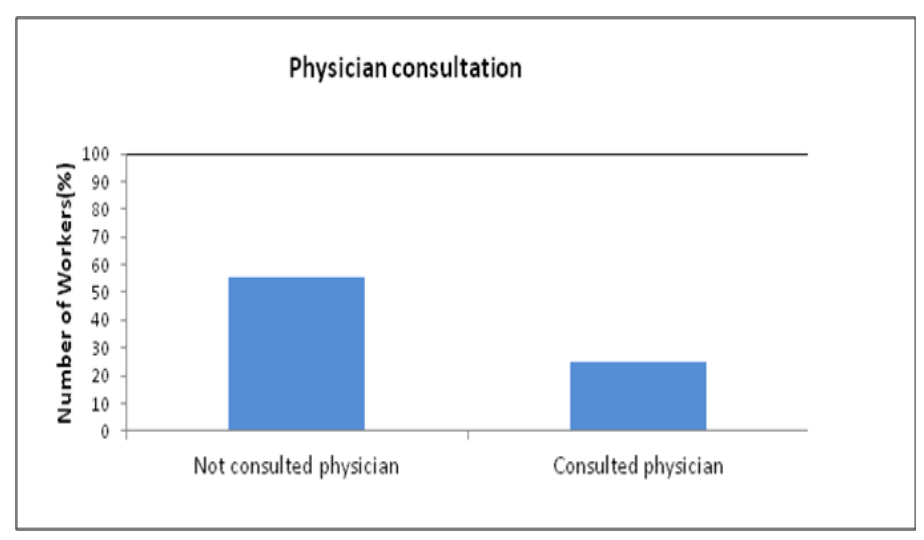

Figure 3 People had trouble and not consulted a physician.

Table 3 Relationship of Occupational stress factors with perceived MSD disorders

\begin{tabular}{|c|c|c|c|c|c|}
\hline SI. no & Stress factors & $\begin{array}{l}\text { MSD - N } \\
(\%)\end{array}$ & $\begin{array}{l}\text { Odds } \\
\text { ratio }\end{array}$ & $95 \% \mathrm{Cl}$ & p-value \\
\hline I & Things happening out of control $(|3|)$ & $116(88.5)$ & 6.01 & $2.4225-14.9224$ & 0.0001 \\
\hline 2 & Work pressure (127) & III(87.4) & 10.82 & $4.0897-28.6615$ & $<0.0001$ \\
\hline 3 & Not able to cope up (127) & $113(89.0)$ & 9.31 & $3.6842-23.5423$ & $<0.0001$ \\
\hline 4 & $\begin{array}{l}\text { Work related dissatisfaction (lack of } \\
\text { decision making opportunities) (72) }\end{array}$ & $64(88.9)$ & 2.7 & I.II7I-6.5725 & 0.0275 \\
\hline 5 & Job insecurity (30) & $23(76.7)$ & 0.4712 & $0.2679-1.8388$ & 0.4712 \\
\hline
\end{tabular}




\section{Generalized linear regression between occupational stress and musculoskeletal discomfort}

Generalized linear regression between occupational stress and musculoskeletal disorders found that there is a significant positive relationship between these two variables $(\beta=4.0296, p=0.000194)$ after adjusting for age, gender and common activities that could induce MSD such as frequenting gym.

\section{Discussion}

The present study demonstrates the occurrence of musculoskeletal disorders among the call centre employee in association with different types of work-stress factors experienced by them. About 155 employees were assessed with the mean age of 27.5 years.

Several studies have found the occurrence of musculoskeletal disorders among call centre workers to be the most common issue. ${ }^{5} \mathrm{~A}$ study conducted on UK computer workers showed that $86 \%$ of data processing workers reported musculoskeletal pain and discomfort in the previous year and $56 \%$ reported the problems within the last week. ${ }^{6}$ Higher prevalence of MSDs in employees reporting stress factors was statistically significant in the current study which is similar to what was reported in another study where the authors found a significant relationship between the pressures of job demands and musculoskeletal disorders $(\mathrm{p}=0.01){ }^{18}$ This association clearly indicates that work stress could be an influencing factor on the prevalence of MSD in exposed employees. ${ }^{12}$ The frequency of MSD was found to be significantly higher in workers with job stress/strain in a call centre in France ${ }^{5}$ which is similar to the results obtained in the present study where significant association between job stress and prevalence of MSDs was observed (X-squared $=30.8858, \mathrm{df}=1$, $\mathrm{p}$-value $=2.737 \mathrm{e}-08$ ).

The phone handlers were provided with good head phones, a comfortable work station and + ergonomic chairs. The company also provided the workers with good welfare facilities such as well equipped and fully functional canteen, bathrooms and a resting-room (or sick-room) for the employees. The company also had tie-up with a clinic nearby in case of any health emergency or accidents for its employees. Provision of comfortable physical office workspace had minimal influence on the employee dissatisfaction as the employees who were handling phone calls. Physical discomfort was not perceived and reported as a major stressor for development of MSD by the respondents in this study in comparison to other work-related stressors. Among the employees who complained of MSDs as well as stress had perceived that 'things happening out of control' (88\%) as the major stressor. The following reasons including the fact that call handlers have little control over the time spent on phone, the kind of client at the other end, limit of choice in their work, limit of authority to make decisions to satisfy the client etc. may be attributed ${ }^{19}$ to the stress caused by 'things happening out of control'. The high work pressure as perceived by the respondents could be attributed to the pressure to complete targets within the time frame with no extra advantage or consideration given for handling difficult callers/technical snags etc. which is common among call centres, along with active efforts by managers to increase utilization of employees' time by reducing the time spent between calls. ${ }^{20}$ One of the major reason for the stress out of 'work-related dissatisfaction' could be due to limitation in task variety, as the call handlers job entails to attend calls over and over again, with no scope for variety or change. ${ }^{20}$

Similar to other studies ${ }^{21}$ stress due to higher workload and workrelated dissatisfaction was reported in this study by the respondents as having higher work volume, many a times unclear/uncertain about their role in resolving the clients' demands and conflicts with the client and/or the supervisors/managers due to the demands placed upon them. Importantly respondents in this, about $40 \%$ of the respondents were stressed by the fact that they could not use their skills and abilities to the full extent in their job. Also, the new finding that emerged from this study is that in spite of training and language orientation to handle English speaking clients from North America and Europe, there is an element of stress that is faced by almost all non-English speaking call handlers due to perceived insufficiency in language, which was not reported in other studies ${ }^{21}$ including the studies from non-English speaking countries.

The most reported MSD among the reporters was prevalent neck pain can be attributed to the repetitive strain injury since they use a fixed-line headset or traditional headset for the entire duration of their work and improper sitting postures that vary between individuals. ${ }^{22}$ Furthermore, physiologically the psychological stressors would act to alter the sensitivity of muscle spindles, whose density is particularly high in the neck region, resulting in the long lasting activation of lowthreshold motor units, known as Cinderella fibers ${ }^{23}$ that could cause neck pain. In the current study, a significant association between the tenure of employment and prevalence of MSD ( $t=37.108$, $\mathrm{p}$-value $<2.2 \mathrm{e}^{-16}$ ) was observed especially with working in the same type of job had a significant influence on the prevalence of MSDs. Similar results in an Italian study also stated one of the reasons for neck \& shoulder related MSD symptoms was long seniority in the Call Centre and psychological stress associated with it were significantly associated. ${ }^{12}$

MSDs are really disabling when it lasts for prolonged duration which can result in chronic sickness, absence and loss of productivity at work, having a dramatic impact on the individuals' ability to stay in the labor market and remain productive ${ }^{18}$ apart from reducing the quality of the life for the individual. ${ }^{24}$ Though such situation warrants consultation with the physician to improve the health condition of the employee, in the current study, it was found that only one-fourth of the affected people went to consult a physician $(25.8 \%)$, whereas the others quoted reasons 'for not consulting' as

a. Long duration of work \& overtime to take out time for doctor's visit on weekday

b. Lack of time to visit physician due to personal commitments on holidays,

c. Complacency and ignorance about the magnanimity of the issue and 4) self-treatment with local pain relievers and medication.

\section{Limitations}

The limitation of the cross sectional study is recognized with a small sample size and that there is been inaccurate recalls of information and does not use any physical instrument to assess the musculoskeletal disorders. However, self -report measurement have been recognized as useful in occupational health surveillance programs for office work environments and this study could be a forerunner for future detailed studies. 


\section{Conclusion}

The current study is the one of the few studies conducted in Indian call centres to explore the association between occupational psychological stress and musculoskeletal disorders among call centre workers. 155 call centre workers recruited in the study responded to two standard validated questionnaires to report their perceptions on work-related psychosocial stress and MSD complaints. The statistical analysis demonstrates the following:

A. Perceived occupational/workplace stress has a significant positive association with prevalence of MSDs complaints among call centre workers.

B. $93.5 \%$ reported experiencing work-related stress and $81.3 \%$ reported MSDs during previous 12 months, with 'things happening outside of control at work' ranking the highest risk factor for MSD among the workplace stressors.

C. Physical comforts at work such as using head phones and ergonomic chairs were perceived as "not significantly" improving the frequency of MSD experienced by the study participants in the neck region as compared to the adverse MSD effects caused by the stress factors. Linear regression shows positive association between stress and MSD among workers after adjusting for age, gender and known MSD causes such as gym activities $(\beta=4.0296$, $\mathrm{p}=0.000194)$.

D. Appropriate interventions to reduce exposures influencing both work-related psychological stress as well as MSDs, like providing with ergonomic furniture \& training, creating job enlargement and implementing job rotation will help improve the occupational health of call centre workers.

\section{Acknowledgements}

The authors highly acknowledge and thank the Department of EHE, Sri Ramachandra University, Chennai for providing them this platform for carrying out the work. The authors are also grateful to the management of the Call centre for their kind co-operation that enabled us to pursue our research successfully.

\section{Conflict of interest}

The author declares no conflict of interest.

\section{References}

1. Ramanuj V. Mental and Physical health related problems of Call centre workers. NHL Journal of Medical Sciences. 2014;3.

2. Hales TR, Sauter SL, Peterson MR, et al. Musculoskeletal disorders among video display terminal users in a telecommunication company. Ergonomics. 2007;37(10):1603-1621.

3. Johnston V, Jull G, Souvlis T, et al. Interactive effects from self reported physical and psychoscocial factors in the workplace on neck pain and dosability in female office workers. Ergonomics. 2010;53(4):502-513.

4. Griffiths KL, Mackey MG, Adamson BJ. The impact of accomputerized work environment on professional groups and behavioural and physiological risk factors for musculoskeletal symptoms: a literature review. J Occup Rehabi. 2007;17(4):743-765.

5. Charbotel B, Croidieu S, Vohito M, et al. Working condition in call centres, the impact on employee health: a transversal study part II. Int Arch Occup Environ Health. 2009;82(6):747-756.
6. Woods V. Musculoskeletal disorders and visual strain in intensive data processing workers. Occup Med. 2005;55(2):121-127.

7. Yoon J, Yi K, Kim S, et al. The relationship between occupational stress and musculoskeletal symptoms in call centre workers. Korean J Occup Environ Med. 2007;19(4):293-303.

8. Lin YH, Chen CY, Lu SY. Physical discomfort and psychosocial job stress among male and female operators at telecommunication call centres in Taiwan. Appl Ergon. 2009;40(4):561-568.

9. Lin YH, Chen CY, Lu SY. Perceived job stress and health complaints at a bank call centre: comparison between inbound and outbound services Ind Health. 2010;48(3):349-356.

10. Kerstin N. Call centre work: characteristics, physical and psychosocial exposure and health related outcomes. Sweden: Linköping University; 2005:1-64.

11. Ferreira M Jr, Saldiva P. Computer-telephone interactive tasks: predictors of musculoskeletal disorders according to work analysis and workers' perception. Appl Ergon. 2002;33(2):147-153.

12. d'Errico A, Caputo P, Falcone U, et al. Risk factors for upper extremity muculoskeletal symptoms among call centre workers. J Occup Health. 2010;52(2):115-124

13. Sudhashree VP, Rohit K, Shrinivas K. Issues and concerns of health among call centre employees. Int J OccupEnvt Med. 2005;9(3):129-132.

14. Kesavachandran C, Rastogi SK, Das M, et al. Working conditions and health among employees at information technology - enabled services:a review of current evidence. Indian J Med Sci. 2006;60(7):300-307.

15. Mehta RK, Parijat P. Associations between psychosocial risk factors and musculoskeletal disorders: application to the IT profession in India. Work. 2012;41 Suppl 1:2438-2444.

16. Bhanderi D, Choudhary S, Parmar L, et al. Influence of psychosocial workplace factors on occurrence of musculoskeletal discomfort in computer operators. Indian J Community Med. 2007;32(3):225-226.

17. Cohen S, Kamarck T, Mermelstein R. A global measure of perceived stress. J Health Soc Behav. 1983;24(4):385-396.

18. Zakerian SA, Subramaniam ID. The relationship between psychosocial work factors, work stress and computer-related musculoskeleta discomforts among computer users in Malaysia. Int J Occup Saf Ergon. $2009 ; 15(4): 425-434$

19. Sprigg CA, Smith PR, Jackson PR. Psychosocial risk factors in call centres: An evaluation of work design and well-being. UK: HSE; 2003:1-92.

20. Guirdham M. Culture and communication. In: Communicating across cultures at work. 2nd ed. Hound mills, England: Palgrave Macmillan; 2005:87-105.

21. Basso G. Call centre helper. 2016.

22. Hagg G. Static workloads and occupational mylagia-A new explanation model. Electromyogr Kinesiol. 1991;9:141-144.

23. Zheltoukhova K, O' Dea L, Bevan S. Taking the strain: The impact of musculoskeletal disorders on work and home life. The Work Foundation. 2012;1-60.

24. Roux $\mathrm{CH}$, Gullemin F, Boini $\mathrm{S}$, et al. Impact of musculoskeletal disorders on quality of life: an inception cohort study. Ann Rheum Dis. 2005;64(4):606-611. 